\title{
New Standpoint of ALT Test for Blood Safety in Dongguan Blood Center
}

\author{
Ziyi He, Fuping Liu, Dewen Wang, Jialin Che \\ Dongguan Blood Center, Dongguan, China \\ Email: zyhe 8@163.com
}

Received 10 February 2014; revised 10 March 2014; accepted 17 March 2014

Copyright (C 2014 by authors and Scientific Research Publishing Inc.

This work is licensed under the Creative Commons Attribution International License (CC BY). http://creativecommons.org/licenses/by/4.0/

(c) () Open Access

\begin{abstract}
Objective: To investigate the relationship between the single ALT positive (ELSIA-HBV/HCV negative) and NAT-HBV/HCV on blood donor samples. Methods: 28710 samples were surveyed retrospectively from Dec. 2010 to Dec. 2011. ALT was detected by rate method, and the single ALT positive samples were detected by ELSIA-HBV/HCV and NAT-HBV/HCV. The relationship between the single ALT positive and NAT-HBV/HCV were analyzed. 21 samples, values in $40 \mathrm{U} / \mathrm{L} \leq \mathrm{ALT} \leq 70 \mathrm{U} / \mathrm{L}$, were selected at random from 2516 samples with single ALT positive, which were second detected by ELISA and NAT in the second donation. Results: 2516 (8.74\%) single ALT positive samples (ELSIA-HBV/HCV negative) were found in 28710 donors. Among these samples, 8 (2.8/10000) positive were detected by NAT, including 5 HBV-DNA-positive and $3 \mathrm{HCV}$-RNA-positive. Obviously, positive rate of NAT from the donors whose ALT value $\leq 70 \mathrm{U} / \mathrm{L}$ were lower than those of $\geq 71 \mathrm{U} / \mathrm{L}$ $(P<0.01) .21$ donors were investigated in the second donation in following 153 to 401 days, All samples were negative by ELISA-HBV/HCV and NAT-HBV/HCV. Conclusions: Donors with single ALT positive (value in $40 \mathrm{U} / \mathrm{L}-70 \mathrm{U} / \mathrm{L}$ ) are not likely to become $\mathrm{HBV} / \mathrm{HCV}$ virus carriers or $\mathrm{HBV} / \mathrm{HCV}$ patients after half or one year. So it is to set ALT abandone threshlod to $\leq 70 \mathrm{U} / \mathrm{L}$ can ensure blood safety, and reduce blood abandone in our center.
\end{abstract}

\section{Keywords}

Blood Donor; ALT; NAT-HBV/HCV; ELISA-HBV/HCV; Investigation

\section{Introduction}

ALT (Alanine aminotransferase), as a non-specificity test, was often called in question in blood screening; The 13th ISBT (International Society Blood Transfusion) has made a investigation for 26 countries and areas; some was not performed ALT test or to change its abandone threshold value to $<120 \mathrm{U} / \mathrm{L}$. The European Union has 
defined HBsAg, anti-HIV1/2 and anti-HCV test as mandatory, but ALT test free [1]. In Germany, The highest limit value of ALT was circumscribed to 3 times (131.7 U/L) the upper limit of normal in male, 2.5 times (86.0 $\mathrm{U} / \mathrm{L}$ ) in female. The other European Union countries made ALT test as recommendation and circumscribed the highest limit value to its 2 times the upper normal limit; in Japan, it is set to $60 \mathrm{U} / \mathrm{L}$, in China, ALT test has defined as a mandatory and set its abandone threshold value to $\geq 40 \mathrm{U} / \mathrm{L}$, because the Law of the People's Republic of China on Blood donor has been circumscribed and the adult reference value is 5 - $40 \mathrm{U} / \mathrm{L}$. Someone has already proposed some different standpoint [2], but all are lack of reliability. For these reasons, we take this study in order to establish a new ALT abandone threshold value and to provide theoretical basis for ALT test in blood screening in our center.

\section{Materials and Methods}

The study was approved by the Ethics Committee of Dongguan blood center and all aspects of the study comply with the Declaration of Helsinki.

\subsection{Investigation Objects}

28710 blood donors' samples were surveyed retrospectively in our center from Dec.2010 to Dec. 2011, including male 14,036, female 14,674, the age range from 18 to 45 years old, The median age are 28 years old. Routine health check were according to the Health examination criteria of blood donors (GB18467-2011) (The national standard of the People's Republic of China).Main blood donation population were company staff, colleges and universities, soldier and urbanian.21 single ALT positive samples, ALT value in 40U/L $\leq$ ALT $\leq 70 \mathrm{U} / \mathrm{L}$, were stratified at random sampling from 2516 single ALT positive blood donors as the investigation objectives, which were exhorted to take part in the second blood donation in the following half or one year, all blood samples were second detected by ELISA(enzyme-linked immuno sorbent assay)-HBV/HCV and NAT-HBV/HCV.

\subsection{Reagent and Equipment}

ALT reagent were provide by Shanghai FuXing Long March pharmaceuticals company (Lot number: BA8306); HBV, HCV nucleinic acid reagent were provide by Roche company (Lot: H08595、H08606); ELSIA-HBV; ELSIA-HCV reagent were provide by SORIN company (Lot: 0370540A,9011610A1); TECAN freedom evo clinical were provide by Switzerland TECAN; auto-ELISA analysis system and DADE BEHRING Xpand were provide by DADE BEHRING; KUBOTA 8420 centrifugal machine were provide by KUBOTA company; Roche COBAS Ampli Screen were provide by Roche company.

\subsection{Test Methods}

ALT were detected by rate method with two different reagents respectively, the instrument were DADE BEHRING Xpand and SUNRISE automatic enzyme-linked immunity analyzer, The single ALT positive samples were ELSIA-HBV/HCV/HIV negative, which were detected two times with different reagents, and were detected NAT-HBV/HCV/HIV with Roche COBAS Ampli Screen. The NAT-HBV/HCV process as fellow: Take $1000 \mu \mathrm{L}$ plasma from 24 blood donors' samples (each about $42 \mu \mathrm{L}$ ) into one tube as a reaction pool, 10 pools as a Ringer, and every Ringer have a positive and a negative control; Nucleinic acid extraction and purification were performed by Roche MagNA Pure LC, all tests are added interior standard preparation in order to control the quality in whole process, Nucleinic acid amplification and semi-quantitative detection were performed by Roche COBAS Ampli Screen; if the reaction pools were negative, it means 24 samples in this pool were NAT-HBV/HCV/HIV negative, if anyone pool is positive, then again every 6 plasma mixed into a reaction as another pool, so this positive pool including 24 suspicious samples, it can be mixed into 4 pools, if anyone of these 4 pools is positive, it should detect each single sample, until the NAT-HBV or NAT-HCV positive sample were confirmed.

\subsection{Statistics Analysis}

The statistics software SAS8.1 are adopted in this study, numeration data with exact probability of chi-square criterion, $P<0.05$ have statistical significance difference. 


\section{Results}

\subsection{The Results Analysis of the Single ALT Positive on Blood Donors by NAT-HBV/HCV Tests}

The single ALT positive rate is $8.74 \%$ (2516/28710); only $8(0.3 \%$, 8/2516) NAT-HBV/HCV positive samples were detected from 2516 blood donors, including 5 HBV-DNA-positive and 3 HCV-RNA-positive. ALT value distribution as follow: One of them is between 71 - $80 \mathrm{u} / \mathrm{L}, 5$ in 81 - $90 \mathrm{u} / \mathrm{L}, 1$ in 91 - $100 \mathrm{U} / \mathrm{L}, 1>121 \mathrm{u} / \mathrm{L}$, respectively. Cumulative frequency of single ALT positive value in $40-50 \mathrm{U} / \mathrm{L}$ were $14.98 \%$, as in $40-70 \mathrm{U} / \mathrm{L}$ were $74.92 \%$. The NAT-HBV positive rate in ALT $\leq 70 \mathrm{U} / \mathrm{L}$ were lower than those of ALT $\geq 71 \mathrm{U} / \mathrm{L}(P<0.05)$ significantly. ALT $\leq 80 \mathrm{U} / \mathrm{L}$ and ALT $\geq 81 \mathrm{U} / \mathrm{L}$ have significance $(P<0.01)$, too. But it has not significance between ALT $\leq 90 \mathrm{U} / \mathrm{L}$ and ALT $\geq 91 \mathrm{U} / \mathrm{L}$. the NAT-HCV positive rate in ALT $\leq 100 \mathrm{U} / \mathrm{L}$ were lower than those of ALT $\geq 101 \mathrm{U} / \mathrm{L}(P<0.05)$, and It has significance between ALT $\leq 110 \mathrm{U} / \mathrm{L}$ and ALT $\geq 111 \mathrm{U} / \mathrm{L}(P<$ 0.05). See Table 1.

\subsection{The Fellow-Up Investigate of the Single ALT Positive Blood Donors with Value in $40 \mathrm{U} / \mathrm{L} \leq \mathrm{ALT} \leq 70 \mathrm{U} / \mathrm{L}$}

2516 donors with single ALT positive, 21 blood donors with single ALT positive were selected at random from those with the ALT value in 40U/L $\leq$ ALT $\leq 70 \mathrm{U} / \mathrm{L}$ and NAT-HBV/HCV negative, These 21 blood donors were investigated when he took part in the second blood donation in the following 153 to 401 days, their blood samples were detected by ELISA-HBV/HCV and NAT-HBV/HCV, The results were all negative, So these blood is confirmed as qualified and be applied to clinical. 5 blood donors take part in the third donor in the follows 54 to 206 days and those blood samples were all negative by ELISA-HBV/HCV and NAT-HBV/HCV. Among those blood donors only one takes part in PLT donor for 5 times in the follow days and is negative by ELISA-HBV/HCV and NAT-HBV/HCV. See Table 2.

\section{Discussion}

Alanine aminotransferase (ALT) is one of the enzyme in term of its catalyses activity of alanine and $\alpha$-ketoglutaric acid; serum content is much lower than it in liver cells, where the content goes up to the highest level (about 2850U). ALT has important clinical value for the preventative cure and diagnose of hepatitis. It also considered as an important target for the blood donation screening. Due to the limitation usage of ELISA test at early stage, ALT test has significant role in anti-PT-NANB (syphilis, Non-A non-B hepatitis) prevention [3]. In addition to HBV and HCV that can lead to hepatitis, related viruses are also HAV, HEV, HCV, TTV, HAV and

Table 1. The results analysis of the single positive ALT on blood donors by NAT-HBV/HCV test.

\begin{tabular}{|c|c|c|c|c|c|c|c|c|}
\hline \multirow{2}{*}{ ALT（U/L） } & \multirow{2}{*}{$\begin{array}{l}\text { ALT positive } \\
\text { Num }^{*}\end{array}$} & \multirow{2}{*}{$\begin{array}{l}\text { Accumulative } \\
\text { frequency (\%) }\end{array}$} & \multicolumn{2}{|c|}{ NAT-HBV } & \multirow{2}{*}{$\mathrm{P}^{\#}$} & \multicolumn{2}{|c|}{ NAT-HCV } & \multirow{2}{*}{$\mathrm{P}^{\#}$} \\
\hline & & & + & - & & + & - & \\
\hline $40-50$ & 377 & 14.98 & 0 & 377 & 1.000 & 0 & 377 & 1.000 \\
\hline $51-60$ & 779 & 45.94 & 0 & 779 & 0.066 & 0 & 779 & 0.250 \\
\hline $61-70$ & 729 & 74.92 & 0 & 729 & 0.001 & 0 & 729 & 0.016 \\
\hline $71-80$ & 252 & 84.94 & 1 & 251 & 0.002 & 0 & 252 & 0.003 \\
\hline $81-90$ & 201 & 92.93 & 3 & 198 & 0.307 & 2 & 199 & 0.198 \\
\hline $91-100$ & 92 & 96.58 & 1 & 91 & 1.000 & 0 & 92 & 0.090 \\
\hline $101-110$ & 52 & 98.65 & 0 & 52 & 1.000 & 0 & 52 & 0.04 \\
\hline $111-120$ & 10 & 99.05 & 0 & 10 & 1.000 & 0 & 10 & 0.028 \\
\hline$>121$ & 24 & 100.00 & 0 & 24 & & 1 & 23 & \\
\hline Total & 2516 & & 5 & 2511 & & 3 & 2513 & \\
\hline
\end{tabular}


Table 2. The investigation of the single positive ALT blood donors with in $40 \mathrm{U} / \mathrm{L} \leq \mathrm{ALT} \leq 70 \mathrm{U} / \mathrm{L}$.

\begin{tabular}{|c|c|c|c|c|c|c|c|c|c|}
\hline NO. & $\begin{array}{l}\text { Blood donors } \\
\text { bar code }\end{array}$ & Repeat times & ALT & $\begin{array}{l}\text { First follow-up } \\
\text { time(D) }\end{array}$ & $\begin{array}{c}\text { ELISA- } \\
\text { HBV/HCV }\end{array}$ & $\begin{array}{c}\text { NAT-HBV } \\
\text { /HCV }\end{array}$ & $\begin{array}{c}\text { Second fol- } \\
\text { low-up time(D) }\end{array}$ & $\begin{array}{l}\text { ELISA- } \\
\text { HBV/HCV }\end{array}$ & $\begin{array}{c}\text { NAT-HBV } \\
\text { /HCV }\end{array}$ \\
\hline 1 & 7048983 & 4 & 44 & 369 & Neg & Neg & & & \\
\hline 2 & 7054296 & 2 & 42 & 220 & Neg & Neg & & & \\
\hline 3 & 7025312 & 18 & 40 & 189 & Neg & Neg & 151 & Neg & Neg \\
\hline 4 & 7053830 & 4 & 40 & 264 & Neg & Neg & & & \\
\hline 5 & 7049812 & 3 & 44 & 304 & Neg & Neg & & & \\
\hline 6 & 7049806 & 3 & 55 & 275 & Neg & Neg & & & \\
\hline 7 & 7045203 & 11 & 69 & 153 & Neg & Neg & 137 & Neg & Neg \\
\hline 8 & 7049853 & 3 & 61 & 217 & Neg & Neg & & & \\
\hline 9 & 7053411 & 3 & 58 & 223 & Neg & Neg & & & \\
\hline 10 & 7053318 & 3 & 61 & 278 & Neg & Neg & & & \\
\hline 11 & 7036997 & 4 & 60 & 214 & Neg & Neg & 196 & Neg & Neg \\
\hline 12 & 7040541 & 4 & 70 & 253 & Neg & Neg & & & \\
\hline 13 & 7037358 & 3 & 66 & 216 & Neg & Neg & & & \\
\hline 14 & 7040549 & 4 & 44 & 251 & Neg & Neg & 206 & Neg & Neg \\
\hline 15 & 7040396 & 2 & 50 & 248 & Neg & Neg & & & \\
\hline 16 & 7040481 & 4 & 51 & 231 & Neg & Neg & & & \\
\hline 17 & 7017486 & 3 & 60 & 346 & Neg & Neg & & & \\
\hline 18 & 7042866 & 3 & 49 & 235 & Neg & Neg & & & \\
\hline 19 & 7047510 & 4 & 48 & 260 & Neg & Neg & 54 & Neg & Neg \\
\hline 20 & 7036969 & 2 & 58 & 401 & Neg & Neg & & & \\
\hline 21 & 7058449 & 2 & 66 & 355 & Neg & Neg & & & \\
\hline
\end{tabular}

HEV is fecal-oral transmission, but is not blood transmission; HGV and TTV can spread by blood transfusion, but its relationship between hepatitis infection and pathogenic is still not clear. Around the world, no country now detects these four kinds specific virus. So the ALT as an alternative indicator, the reason is not sufficient to replace the specific indicators of HAV, HEV, HCV, TTV. With the enhancement in sensitivity and specificity of ELISA diagnosis reagent, the specificity of the ALT value is declining gradually; many factors can lead to abnormal increased ALT nonspecific besides liver disease, such as cold, sleep insufficiency, medicine, bodyweight overload, habits and customs, temperature of specimen transportation and preserved condition. Therefore, the relationship between the ALT positive blood donors and the NAT-HBV/HCV may provide the important reference for the blood safety and disease prevention. Some research shows that it has no correlation between the positive ALT and ELISA-HBV, but it has correlation with ELISA-HCV [4]. ELISA-HCV positive rate in abnormal ALT population is significantly higher than in normal [5]. Sankary et al. [6] detected the HBV-DNA and HCV-RNA from 375 ALT higher level samples, but it has not infected HBV or HCV, so they revealed that the ALT test was unnecessary for prevent the blood transfusion after HBV and HCV serology test. Thus the ALT test to detect or predict HBV and HCV infection was meaningless. A prospective study was conducted in 166 of 645 eligible blood donors from three American Red Cross regions whose ALT was $\geq 120$ U/L and whose standard donor screening tests were negative. In the blood donation population, of whom 124 (75\%) were followed. Samples obtained from the index donation, at enrollment (1 month), and at follow-up (6 months) underwent the standard donor screening tests. No participants were positive for HCV RNA. These data suggest that some blood donors' ALT value was 120 U/L or higher, and HBV or HCV infection of serological marker detection is nega- 
tive, but these donors are still suspicious of HBV or HCV infected. Continued ALT testing may contribute little [7]. Reported in Brazil there are 71 blood donors with single ALT positive and anti-HBV/HCV negative, these donors were followed-up for two years, and none of these donors were detected HBV or HCV positive. This fully shows that ALT detection of HBV, HCV infection window period does not have any significance [8]. But in china, the single positive ALT is the main reason of blood abandonment, so it is important to study whether blood donor is the HBV/HCV carrier or incubation period in order to guarantee the blood safety and protection blood recourse.

In this study, 2516 single ALT positive samples were detected in 28,710 blood donors from Dec, 2006 to Dec, 2007 in our center; 8 blood donors' samples with HBV or HCV virus were detected by NAT-HBV/HCV (including $5 \mathrm{HBV}$ and $3 \mathrm{HCV}$ ); it means to cancel ALT test is not fit in our center now, in spite that a great quantity of blood were abandoned and a lot of blood donors were refused to donate blood because of whose ALT value was exceed 40U/L. A possible way proposed is to raise the ALT abandon threshold value. In this study, we disclosed the distribution interval of 8 samples with single ALT positive and NAT positive. One of them is between 71 - $80 \mathrm{U} / \mathrm{L}, 5$ in 81 - $90 \mathrm{U} / \mathrm{L}, 1$ in 91 - 100U/L, $1>121 \mathrm{U} / \mathrm{L}$, respectively. The cumulative frequency of single ALT positive values in $40-50 \mathrm{U} / \mathrm{L}$ was $14.98 \%$, in $40-70 \mathrm{U} / \mathrm{L}$ were $74.92 \%$ and in $40-80 \mathrm{U} / \mathrm{L}$ were $84.94 \%$, respectively. It seems that to raise the abandon threshold value to $80 \mathrm{U} / \mathrm{L}$ is feasible by statistical analysis $(\mathrm{P}<0.05)$, but $1 \mathrm{HBV}-\mathrm{NAT}$ positive were in $71-80 \mathrm{U} / \mathrm{L}$, so we set the abandon threshold value of ALT to $70 \mathrm{U} / \mathrm{L}$.

Whether or not ALT value in 40 - $70 \mathrm{U} / \mathrm{L}$ will be HBV/HCV virus carrier or have been HBV/HCV patients in the following half or one years, we take a follow-up investigation on 21 blood donors with single ALT positive whose ALT value is in $40-70 \mathrm{U} / \mathrm{L}$, which were selected at random from 2516 samples with single ALT positive. All those blood donors were requested to take part in blood donor at least 1 times in the following half or one year, and the blood donors came back and their blood samples were all negative by ELISA-HBV/HCV and NAT-HBV/HCV. So we consider that it can raise the ALT abandon threshold value to $70 \mathrm{U} / \mathrm{L}$, which is reasonable, and that ALT test is necessary now, because virus hepatitis infection population in china is enormous and virogene distribution is extremely variable [5] [6] [9]. So we set the ALT abandon threshold value to $\leq 70 \mathrm{U} / \mathrm{L}$ which can ensure blood safety, save blood, and provide reference for the reasonable and scientific strategy of blood screen. We did not analyzed the effect between the blood donor gender and its value in this study, because the gender ratio of the blood donation male and female in blood donation about were one to one (1:1), and ALT abandoned threshold set in China was less than $40 \mathrm{U} / \mathrm{L}$ now. So we have to distinguish male and female.

Now that it isn't significant whether to raise the ALT reject value or to cancel this test simply, it even may degrade the coefficient of resistance of blood transfusion. If the abandoned threshold is too low, it will waste a great of valuable blood. How to face this dilemma between saving blood and ensuring the safety of the blood; it is necessary to find a better way to solve it. The techniques of NAT are not extensively applied in our center because of the expensive reagent now. At present, because heavy pollution are suffering from hepatitis B in china, hepatitis $\mathrm{C}$ and HIV/AIDS patients or virus carriers are also more growing. The government of China is gradually promoting nucleic acid detection on blood donations, whose purpose is to further shorten the window period of diseases spread, and to try to reduce the incidence of hepatitis B, hepatitis C, HIV, which is the most important thing to protect the health of all Chinese citizens. However, the deficiency blood in clinical in china is very serious. As a non-specific indicator, ALT is the main factor causing blood abandoned, Therefore this paper improves the ALT rejection threshold, prevent qualified blood is wrongly discarded. At the same time, it also does not affect the NAT to reduce the risk of a blood transmission diseases. This mode can be said to be the most beneficial. Therefore, it is necessary to establish a voluntary, low cost, low risk blood donor team which is another way to ensure blood safety in our center.

\section{References}

[1] European Commission, Enterprise Directorate-General; Working Party on Control of Medicines and Inspections. Revision Annex 14 of the EU Guide to Good Manufacturing Practice. Manufacture of Medicinal Products Derived from Human Blood or Blood Plasma. Brussels, European Commission [M].2000.58-64.

[2] Shindo, M., Di Bisceglie, A.M., Biswas, R., et al. (1992) Hepatitis C Virus Replication during Acute in Faction in the Chimpanzee [J]. The Journal of Infectious Diseases, 166, 424-427. http://dx.doi.org/10.1093/infdis/166.2.424

[3] Lee, D.H., Ha, M.H. and Christiani, D.C. (2001) Body Weight, Alcohol Consumption and Liver Enzyme Activity-A 4-Year Follow-Up Study [J]. International Journal of Epidemiology, 30, 766-770. 
http://dx.doi.org/10.1093/ije/30.4.766

[4] Shakil, A.O., Conry-Cantilena, C., Alter, H.J., et al. (1995) Volunter Blood Donors with Antibody to Hepatitis Cvirus: Clinical, Biochemical, Virologic, and Histologic Features [J]. Annals of Internal Medicine, 123, 330-337. http://dx.doi.org/10.7326/0003-4819-123-5-199509010-00002

[5] Alter, H.J., Conry-Cantilena, C., Melpoder, J., et al. (1997) Hepatitis C in Asymptomatic Blood Donors [J]. Hepatology, 26, 29-33.

[6] Sankary, T.M., Yang, G., Romeo, J.M., et al. (1994) Rare Detection of Hepatitis Band Hepatitis C Virus Genomes by Polymerase Chain Reaction in Seronegative Donors with Elevated Alanine Aminotransferase [J]. Transfusion, 34, 656-660. http://dx.doi.org/10.1046/j.1537-2995.1994.34894353458.x

[7] Notari 4th, E.P., Orton, S.L., Cable, R.G., et al. (2001) Seroprevalence of Known and Putative Hepatitis Markers in United States Blood Donors with ALT Levels at Least 120 IU per L [J]. Transfusion, 41, 751-755. http://dx.doi.org/10.1046/j.1537-2995.2001.41060751.X

[8] Gonçales Júnior, F.L., Stucchi, R.S., Papaiordanou, P.M., et al. (1998) Elevated Alanine Aminotransferase (ALT) in Blood Donors: An Assessment of the Main Associated Conditions and Its Relationship to the Development of Hepatitis C [J]. Revista do Instituto de Medicina Tropical de São Paulo, 40, 219-224. http://www.ncbi.nlm.nih.gov/pubmed/9876434

[9] Kao, J.H., Chen, P.J., Lai, M.Y., et al. (2002) Genotypes and Clinical Phenotypes of Hepatitis Virus in Patients with Chronic Hepatitis B Virus Infection [J]. Journal of Clinical Microbiology, 40, 1207-1209.

http://dx.doi.org/10.1128/JCM.40.4.1207-1209.2002 